\title{
Design of Solar Optical Fiber Lighting System for Enhanced Lighting in Highway Tunnel Threshold Zone: A Case Study of Huashuyan Tunnel in China
}

\author{
Xiaochun Qin, ${ }^{1,2}$ Xuefeng Zhang, ${ }^{1}$ Shuai Qi, ${ }^{3}$ and Hao Han ${ }^{1}$ \\ ${ }^{1}$ Beijing Jiaotong University, Beijing 100044, China \\ ${ }^{2}$ Beijing Key Laboratory of Track Engineering, Beijing 100088, China \\ ${ }^{3}$ Hohhot Transportation Bureau, Hohhot 010070, China \\ Correspondence should be addressed to Xiaochun Qin; 110843281@qq.com
}

Received 2 July 2015; Accepted 3 November 2015

Academic Editor: Jong Hak Kim

Copyright ( 2015 Xiaochun Qin et al. This is an open access article distributed under the Creative Commons Attribution License, which permits unrestricted use, distribution, and reproduction in any medium, provided the original work is properly cited.

\begin{abstract}
In this paper, the principle, structural composition, materials, and characteristics of solar optical fiber lighting system were discussed. The different luminance requirements of different zones of highway tunnel were identified on the basis of the analysis of tunnel lighting considering drivers' visually self-accommodating physiological function for luminance change. Taken Huashuyan Tunnel of G109 Highway located in Hohhot of Inner Mongolia in China as the case study, the system design of solar optical fiber lighting for enhanced lighting in threshold zone of highway tunnel was made. It was indicated through calculation that the design length of solar optical fiber enhanced lighting was related to the design speed, longitudinal slope, and overhead clearance of the tunnel, and the design luminance of solar optical fiber enhanced lighting was related to the luminance outside the tunnel, the design speed, and the design traffic flow of the tunnel. Luminance analysis of the solar optical fiber lighting system of Huashuyan Tunnel was made based on the on-site experiment. Also, the 3D illuminance simulation results by DIALux software were made to indicate that the solar optical fiber lighting system in Huashuyan Tunnel still well met the enhanced lighting demand even not considering the contribution of LED lighting.
\end{abstract}

\section{Introduction}

As a kind of natural light guidance system, solar optical fiber lighting can transmit natural light and make lighting based on the total reflection principle of light in fibers made of various sorts of materials like glass or plastic, which can introduce the light from natural or artificial light source into the optical fiber and make light redistribution through the transmission of optical fiber in terms of the lighting needs. Solar optical fiber lighting system has been given more and more attention internationally since 1960s for the characteristics of safety, environmental protection, and nonenergy consumption with the green light source of natural light [1]. China began the research and development of optical fiber lighting in smallscale in the late 1970s [2]. At present, the optical fiber lighting technology has been widely promoted and got practical application in the functional lighting of museums, hospitals, residential, office buildings, and underground places [3-7].

However, it is rarely used in the tunnel lighting, mainly because of the considerable variability in optical properties between optical fiber lighting and traditional lighting system and the big differences in the functional lighting requirements between tunnel and other ordinary buildings. Therefore, the design method of optical fiber lighting system for the tunnel lighting cannot copy that of traditional lighting and the optical fiber lighting for ordinary buildings and cannot be applied directly in tunnel lighting either. Up to the end of 2012, 8000 highway tunnels with more than ten thousand kilometres have been built in China. Along with the increase in construction of highway tunnels, the power consumption of tunnel lighting also increased significantly. Therefore, it is becoming great important to save the lighting 
power consumption under the condition of safe driving and comfortable lighting. With the national supporting policies of energy saving and emission reduction, solar optical fiber lighting system has become an important part of modern energy-saving lighting and would also become a new way of tunnel lighting, with sunlight use, power saving, safety and health, and flexible design and almost without power hidden danger, light source heat, and electromagnetic interference.

Due to the special tubular structure of tunnel and the limitation of human's visually self-accommodating physiological function for luminance change, extreme luminance contrast will occur when the car driver is driving into or pulled out of the tunnel in the daytime, generally visually causing "black hole phenomenon" or "white hole phenomenon," which would bring great threats to the driving safety. Therefore, reinforcing lighting was needed as well in the threshold and exit zone of highway tunnels in addition to the basic lighting, making drivers' eyes accommodate the abrupt changes of luminance from outside tunnel into the tunnel. Basic lighting system, powered by conventional power or PV and wind power generation systems, is generally installed inside along the whole tunnel and required for nonstop working day and night to guarantee the basic luminance in the tunnel. Unlike basic lighting, enhanced lighting system is installed in tunnel threshold zone generally as a supplementary lighting. According to "Specifications for Design of Ventilation and Lighting of Highway Tunnel of China (JTJ026.1-1999)", lights need distributed installation in accordance with a certain luminance gradient in highway tunnel [8]. The design luminance of enhanced lighting is changed with the sunlight luminance outside the tunnel other than a constant value. Generally, enhanced lighting works in a closed-loop adaptive control depending on the sunlight luminance outside the tunnel, which is divided into four grades (sunny, cloudy, overcast, and heavy overcast). However, many enhanced lighting systems in practical projects have not been installed in the automatic control system in accordance with the requirements of sunlight luminance due to the limitations of objective factors like the tunnel located in a remote area or maintenance inconvenience during the system using process. To ensure the driving safety, maximum parameter value of sunlight luminance in summer generally is considered and the enhanced lighting systems with fixed luminance are employed to ensure the work reliability. Researches have shown that, for the medium and long tunnels less than $3000 \mathrm{~m}$ in length, the power consumption of enhanced lighting is about $50 \%$ of the total power consumption of the tunnel lighting [9]. And the less the length of the tunnel is, the greater the proportion of enhanced lighting will be. Therefore, there are a lot of energy wastes in the enhanced lighting system of the highway tunnel in China at present. Nowadays, there are many ways for the tunnel enhanced lighting in the world, including the use of light attenuation measures like planting green trees on both sides in the access zone of the tunnel and laying the materials with high reflectance on both sides inside the tunnel $[10,11]$. The above methods are just auxiliary measures only through reducing the luminance of visual environment or improving the luminance inside tunnel as far as possible to reduce the power burden of enhanced lighting system but not completely solving the practical problems. There are also some researches on lighting system by ordinary solar photovoltaic power generation system at home and aboard, but the low efficiency of solar energy utilization is one of the major technical bottlenecks to promote the application [12-14].

In view of the characteristics of solar optical fiber lighting changing with the outside natural light changing coinciding with the rules of the luminance level of pavement in the tunnel threshold zone adjusting with the outside luminance changing, the application of optical fiber lighting system for enhanced lighting in highway tunnel could greatly save the power consumption of tunnel lighting and maintenance cost of lighting facilities, providing the new ideas and methods for tunnel lighting design as well as further expanding the application scope of solar optical fiber lighting system. However, there are few researches in the relevant filed, especially with full consideration of the problems of the tunnel environment, the demand of highway tunnel lighting of different zones, the performance of the light source, the transmission loss, and the economic efficiency $[15,16]$. Therefore, it is quite necessary and urgent for launching the systematic research on solar optical fiber lighting for tunnel lighting based on the characteristics of optical fiber lighting and the different luminance demand of different zones of the tunnel to explore the new ways of energy saving of tunnel lighting and promote the application of solar optical fiber lighting, which would have important theoretical and practical significance in the sustainable development of highway tunnel lighting.

\section{Materials and Methods}

2.1. The Principle and Structural Composition of Solar Optical Fiber Lighting. Solar optical fiber lighting system, mainly composed of light guiding device-collector, light transmission device-optical fiber, and light output devicelight resource, concentrated the sunlight by collector and transmitted it to the places needing lighting through optical fiber or light pipe and then making diffused reflection [17]. The principle and structural composition of solar optical fiber lighting system were shown in Figures 1 and 2.

\subsection{Materials and Components of Solar Optical Fiber Lighting} System. With the development of new technology and new material, the transmission efficiency of solar optical fiber lighting system gradually improved. There were many different types of optical fiber lighting system. In our study, the materials and components of the solar optical fiber lighting system used for tunnel lighting are as follows.

(1) The Light Concentrating Way of the Light Guiding Device. The light guiding device concentrated light through lens refraction, which used convex lens or Fresnel lens to focus the sunlight on the focal point of the lens and improve the transmission efficiency of optical fiber by the precise positioning of the optical fiber input terminal.

(2) The Operating Mode of the Light Guide Device. The operation mode of the light collector adopted active light 


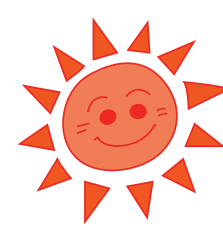

Sunlight

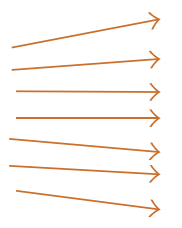

Light collector

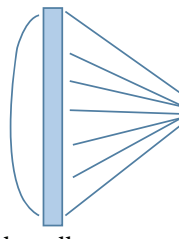

Light transmission device
Optical fiber

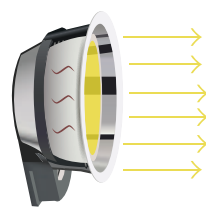

Light output device Optical source

FIgURE 1: The schematic diagram of the solar optical lighting system.

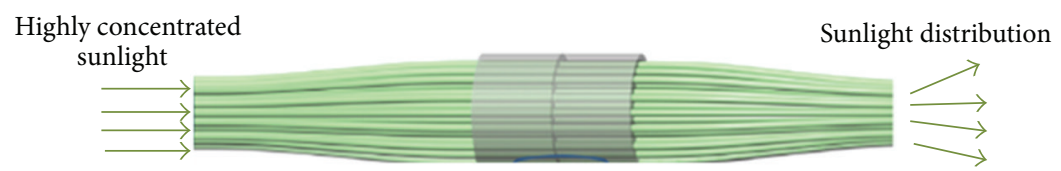

(a)

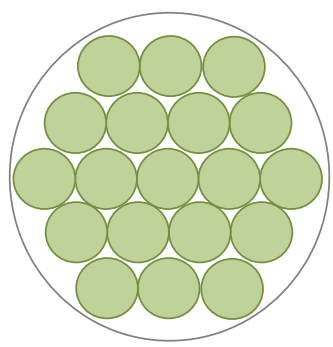

(b)

FIgURE 2: (a) Sunlight transmission through optical fibers. (b) Arrangement of optical fibers to make the fiber bundle.

guiding device, namely, installed solar optical tracking sensor, controller, and related mechanical transmission devices to make collector focus on the sun and obtain a higher solar light efficiency, which was also the operating mode used by the most of the solar optical fiber lighting systems at present.

(3) The Materials Used for Optical Fibers. Three kinds of optical fibers were currently most used including quartz fiber, plastic fiber, and multicomponent glass fiber, and liquid core fiber, hollow fiber, and other fibers were also used. The different kinds of optical fibers had their own characteristics. The transmission efficiency of quartz optical fiber was the highest with the optical loss reaching $0.01 \mathrm{~dB} / \mathrm{m}$ and had a great advantage in long distance transmission but with the relatively high cost. The optical loss of plastic fiber and glass fiber was relatively large with $0.15 / \mathrm{m} \mathrm{dB}$ by contrast, which had some limitations in the distance of optical transmission. But plastic fiber was easy to make into the transfer beam of large diameter to obtain greater luminous flux and high concentrating rate, which now had a wide range of applications [18]. We chosen quartz optical fiber in the study.

(4) The Light Emitting Manner of Light Output Device. The optical fibers with end light emitting were used in the solar optical fiber system for tunnel in this study. Similar to the conventional lighting device, the light emitted through light resources is connecting with the end of optical fiber after being transmitted to a certain position.

2.3. The Characteristics Analysis of Solar Optical Fiber Lighting System. As a new type of lighting system, solar optical fiber lighting system had some advantages that the traditional lighting systems could not match, while there were still some bottlenecks in the practical application, as shown in Table 1.

Based on the analysis of the characteristics (Table 1), it could be seen that the current solar optical lighting system was suitable in the relatively small places with short transmission distance and small lighting area; also, it could be widely used in the cold and wet even flammable and explosive special place, which were good in line with the requirements of tunnel enhanced lighting in the threshold zone.

2.4. The Characteristics Analysis of Tunnel Lighting. The visual uncomfortableness and the visibility reduction would be caused by unsuitable luminance distribution, or the extreme luminance contrast in space or time was called glare. While in daytime especially in summer noon with very strong sunlight, the luminance contrast inside and outside the tunnel was very big. The light intensity dropped suddenly when the vehicle approach the tunnel threshold, and the drivers would have glare and black hole phenomenon visually if the tunnel lighting was not sufficient. Therefore, in order to visually adapt to the rapid changes of luminance inside and outside the tunnel, long tunnel could be divided into five lighting zones: access zone, threshold zone, transition zone, interior zone, and exit zone, as shown in Figure 3. The luminance requirements of different zones depended on the visual phenomenon.

Enhanced lighting system needs to be installed in tunnel threshold or exit zone to make the high luminance outside the tunnel gradually decreased to the low luminance level inside the tunnel, which would make good luminance transition and improve the visual environment in the tunnel through making driver's eyes adapt to the light intensity changes from outside to inside the tunnel and eliminate the driving safety hidden troubles visually. 
TABLE 1: Characteristics analysis of solar optical fiber lighting system.

Energy saving and environmental protection

Safety and health

Advantages

Easy maintenance

Flexible layout

High cost

Disadvantage

Large attenuation in long distance
(1) Light source of clean energy with little energy consumption and artificial lighting power reduction during the day

(2) No heat effect of electric light source

(3) Good energy efficiency

(1) Healthy and comfortable lighting environment of high quality by the control of the output of the ultraviolet ray and infrared ray

(2) Fine safety without the power hidden trouble and electromagnetic interference

(3) The fact that it could be used in the special places in cold and wet weather even in flammable and explosive environment

The collected light was the sunlight all by light guiding device, and it could well meet the requirements only to make good maintenance of the light guiding device of the centralized layout.

The light output device could achieve a variety of forms of light emitting, such as dot, line, and surface, which would give the lighting design more freedom, diversity, and artistry.

The solar tracking device and the quartz optical fiber lighting system with high light transmission efficiency were relatively expensive, so the high cost of the one-time investment and cost performance problem were the major reasons affecting the popularization of light guide lighting system.

Although quartz optical fiber had a high optical transmission efficiency less than $200 \mathrm{~m}$, but its transmission efficiency would drop to $10 \%$ for more than $1000 \mathrm{~m}$.

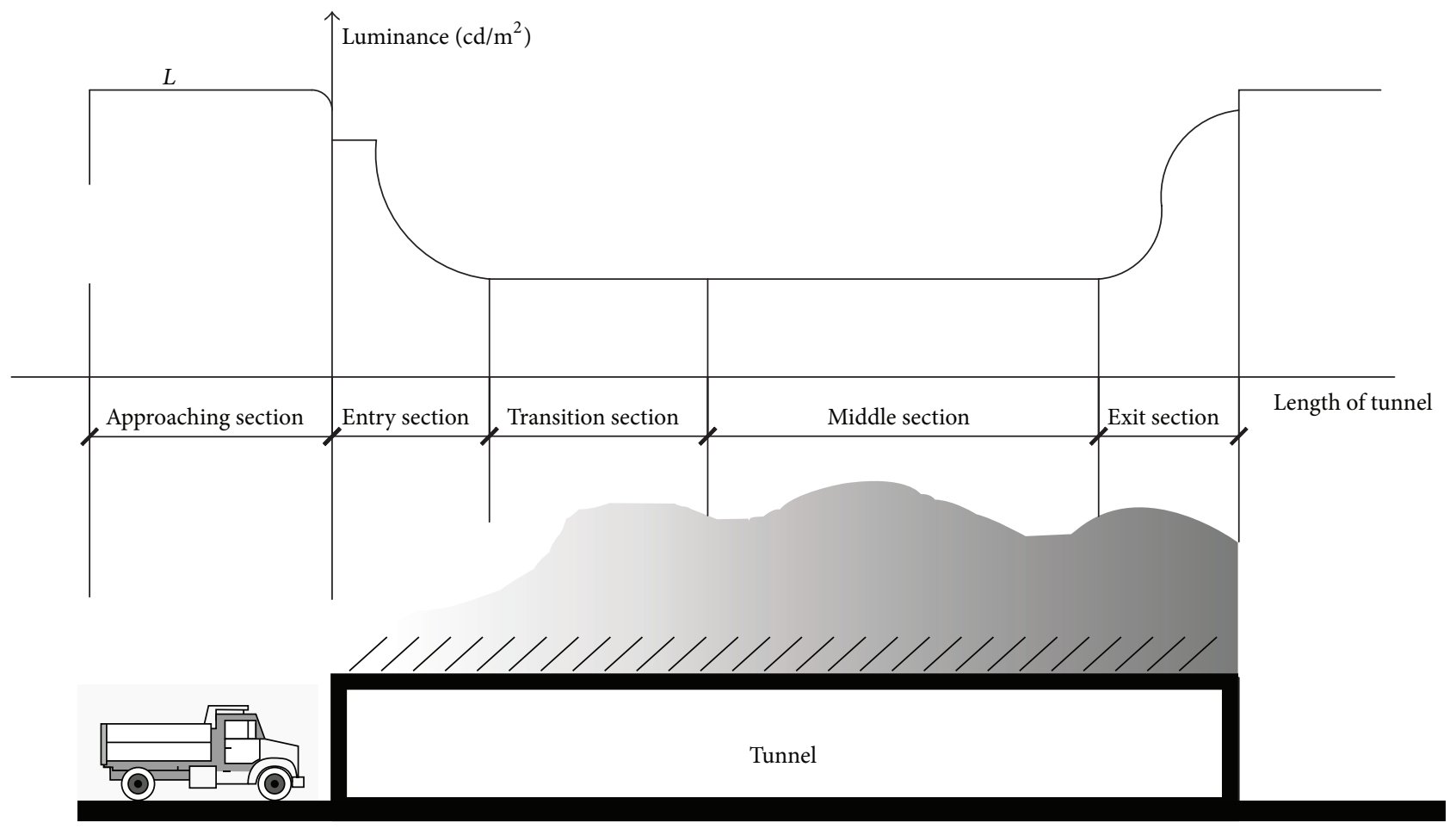

FIGURE 3: The luminance requirements of different zones of the highway tunnel.

2.5. The System Design of Solar Optical Fiber Lighting for Highway Tunnel. The solar optical fiber lighting for highway tunnel provided the enhanced lighting through the light guiding device to collect the sunlight and transmit it by optical fiber to the reflector panel of light output device, as shown in Figure 4.

\section{Results}

Based on the analysis of the characteristics of solar optical fiber lighting system and the lighting requirements of tunnel lighting, the position of the tunnel threshold zone had natural advantage of employing the sunlight. Solar optical fiber 


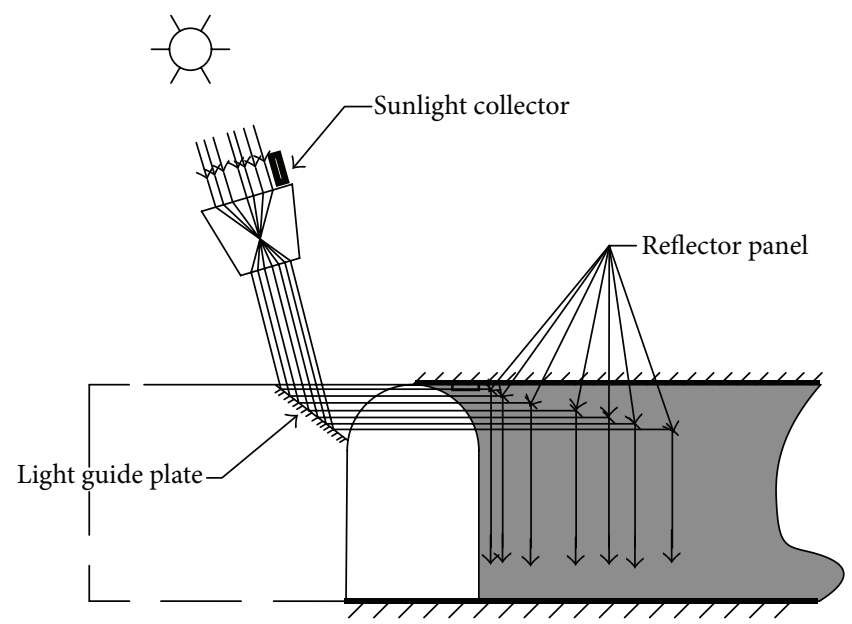

FIgURE 4: The system design schematic of solar optical fiber lighting for highway tunnel.

lighting system well accorded with the law of the luminance of pavement in tunnel threshold zone changing with the changes of luminance outside the tunnel and could save considerable lighting energy consumption, so it would have certain feasibility in enhanced lighting of highway tunnel.

In this paper, we took Huashuyan Tunnel of G109 Highway located in Hohhot of Inner Mongolia in China as the case study, where it belonged to the area of the light climate zone II with the regional annual average illumination of $40 K l_{x} \leq$ $E_{q}<45 K l_{x}$ according to "standard for day lighting design for building (GB 50033-2013) and had relatively abundant solar energy" $[19,20]$. The tunnel was designed in two-lane oneway traffic with the traffic volume more than 700 volumes $/ \mathrm{h}$. The design speed of the tunnel was $60 \mathrm{~km} / \mathrm{h}$ and the design longitudinal slope of the threshold zone was $2 \%$.

3.1. The Design Length Calculation of the Threshold Zone of Huashuyan Tunnel. According to "Specifications for Design of Ventilation and Lighting of Highway Tunnel," the distance of the tunnel threshold zone could be calculated according to the following formula:

$$
D_{\text {th }}=1.154 D_{s}-\frac{(h-1.5)}{\tan 10^{\circ}},
$$

where $D_{\text {th }}$ was the length of the threshold zone, $D_{s}$ was the stopping sight distance, and $h$ was the overhead clearance of the tunnel.

The stopping sight distance $D_{s}$ was related to design speed and longitudinal slope of the tunnel, as shown in Table 2. The design speed of Huashuyan Tunnel was $60 \mathrm{~km} / \mathrm{h}$ with the longitudinal slope in the threshold zone of $2 \%$ and the overhead clearance of $7.2 \mathrm{~m}$. Therefore, according to the above formula, the design length of the threshold zone of the tunnel could be obtained as $30.55 \mathrm{~m}$.

3.2. The Design Luminance Calculation of the Threshold Zone of Huashuyan Tunnel. Because of the high requirement of the tunnel lighting, especially the pavement luminance in the threshold zone as the highest luminance in the tunnel
TABLE 2: The stopping sight distance $D_{s}$ for highway tunnel lighting (m).

\begin{tabular}{lccccccccc}
\hline \multirow{2}{*}{ Design speed $(\mathrm{km} / \mathrm{h})$} & \multicolumn{10}{c}{ Longitudinal slope $\left(^{\circ}\right)$} \\
& -4 & -3 & -2 & -1 & 0 & 1 & 2 & 3 & 4 \\
\hline 100 & 179 & 173 & 168 & 163 & 158 & 154 & 149 & 145 & 142 \\
80 & 112 & 110 & 106 & 103 & 100 & 98 & 95 & 93 & 90 \\
60 & 62 & 60 & 58 & 57 & 56 & 55 & 54 & 53 & 52 \\
40 & 29 & 28 & 27 & 27 & 26 & 26 & 25 & 25 & 25 \\
\hline
\end{tabular}

lighting, the design luminance of solar optical fiber enhanced lighting in the threshold zone could be calculated according to the luminance outside the tunnel, the design speed of the vehicle, and the design traffic flow, as shown in the following formula:

$$
L_{\text {th }}=k \times L_{20}(S) \text {, }
$$

where $L_{\mathrm{th}}$ was the luminance in the threshold zone, $k$ was the reduction coefficient, as shown in Table 3 , and $L_{20}(S)$ was the luminance outside the tunnel.

Because Huashuyan Tunnel in this study had two-lane one-way traffic with the design traffic volume $N \geq 700 \mathrm{v} / \mathrm{h}$ and the design speed of $60 \mathrm{~km} / \mathrm{h}$, the reduction coefficient $k$ was 0.022 . The luminance of outside the tunnel was measured to be 3794 lux in average at noon in a sunny day of April. Therefore, the design luminance in the threshold zone of the tunnel should be 83.47 lux at least according to the calculation.

3.3. The Design of the Solar Optical Fiber Lighting System for Huashuyan Tunnel Enhanced Lighting. The solar optical fiber lighting system contained the sunlight collector, quartz optical fiber for light transmission, and fiber optic irradiator. The sunlight collector was employed in the basis set of 330DS type of Sunshine Masters Series (530 mm in diameter) including acrylic shield, light trap, and circular prismatic diffuser. 
TABLE 3: The reduction coefficient of the luminance in the threshold zone $k$.

\begin{tabular}{lccrr}
\hline \multicolumn{2}{c}{ Design traffic volume $N(\mathrm{v} / \mathrm{h})$} & \multicolumn{2}{c}{$k$} \\
\multicolumn{1}{c}{} & & \multicolumn{2}{c}{ Design speed $(\mathrm{km} / \mathrm{h})$} \\
Two-lane two-way traffic & Two-lane one-way traffic & 100 & 80 & 60 \\
\hline 2400 & $\geq 700$ & 0.045 & 0.035 & 0.022 \\
$\geq 1300$ & $\geq 360$ & 0.035 & 0.025 & 0.012 \\
\hline
\end{tabular}

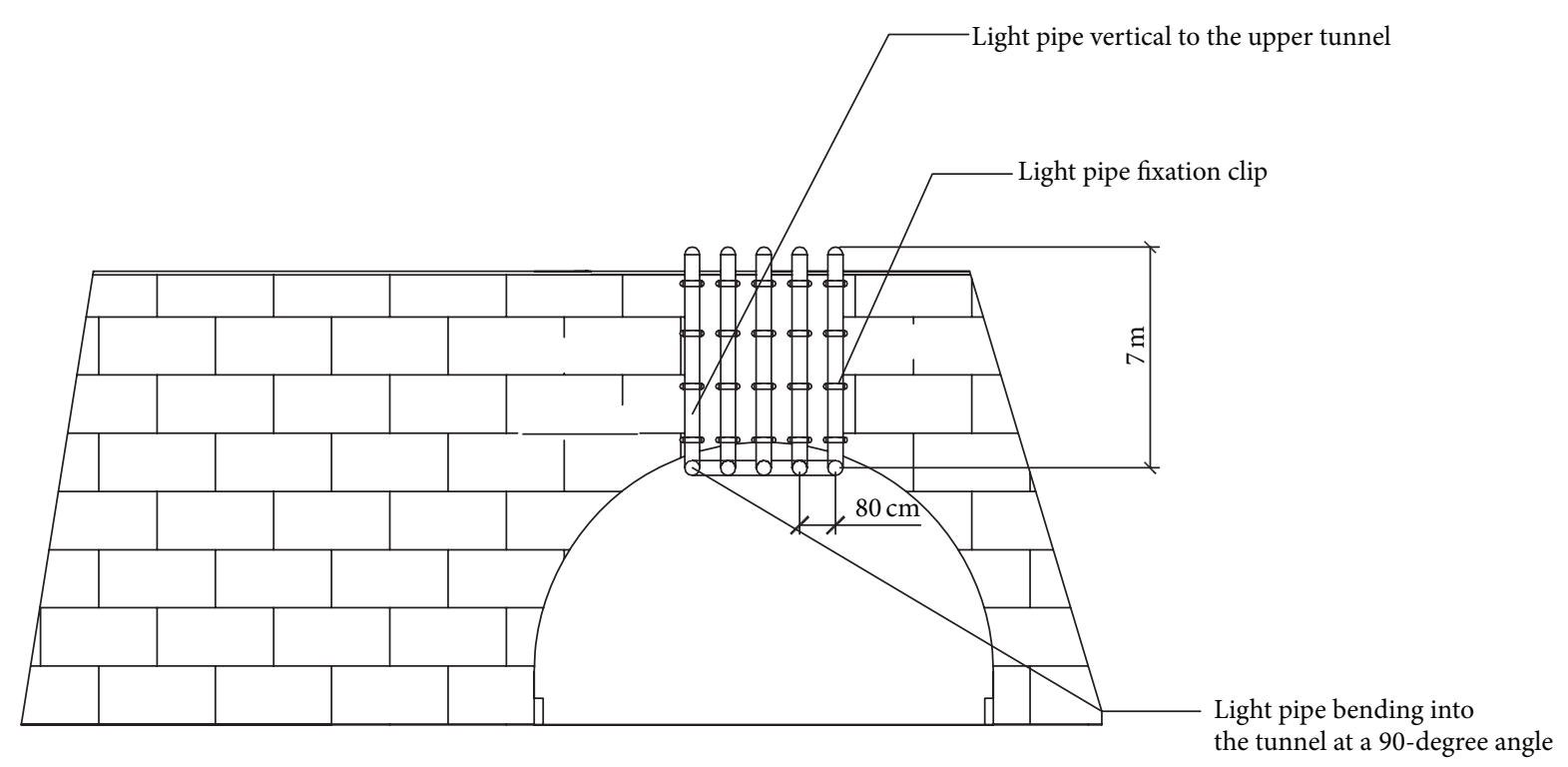

FIGURE 5: Design diagram of solar optical fiber lighting system in vertical zone of Huashuyan Tunnel.

According to the above calculation of the design length of the threshold zone of Huashuyan Tunnel, the total length of solar optical fiber lighting system for Huashuyan Tunnel was $30 \mathrm{~m}$, and the design luminance was set over 83.47 lux. The number of optical guiding devices was determined taking the orientation of the tunnel, the width and height of the tunnel, and the environmental factors outside into consideration. A total of 5 light pipes were installed and the solar optical fiber irradiators were installed at 10 meters from the entry of the tunnel with an interval of 5 meters to the interior tunnel, as shown in Figures 5-8.

3.4. Luminance Analysis of the Solar Optical Fiber Lighting System for Huashuyan Tunnel Enhanced Lighting. The onsite luminance experiment was carried out every hour from 6:30 to $16: 30$ for 5 consecutive days from April 6th to April 10th. Based on the sunny and cloudy condition in spring in Hohhot, the average luminance effects comparison of the solar optical fiber lighting with LED lighting in the central line of the tunnel was made in Figure 9. It could be seen in Figure 9 that the average luminance of solar optical fiber lighting in tunnel threshold zone in daytime was $181.31 \mathrm{~cd} / \mathrm{m}^{2}$ at minimum, which could well meet the basic design demand of $83.47 \mathrm{~cd} / \mathrm{m}^{2}$ [21].

We also used DIALux software to make a luminance simulation to analyze the feasibility of the solar optical fiber lighting system for Huashuyan Tunnel enhanced lighting. The luminance simulation was based on the sunny weather

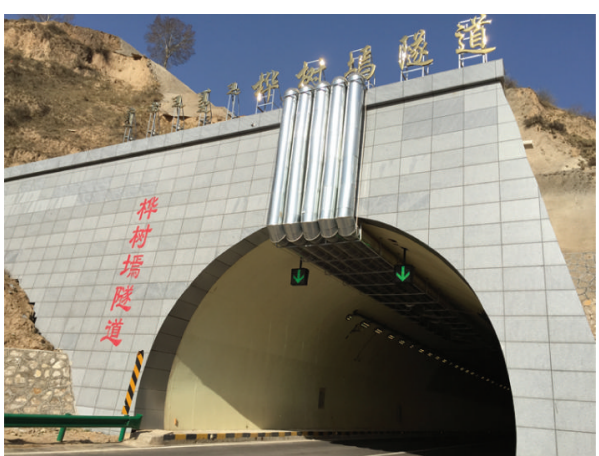

FIGURE 6: Light pipe installation in vertical zone of Huashuyan Tunnel.

conditions with the outdoor average luminance of 45000 lux. The isolux distribution map with the ratio of $1: 251$ and the illuminance of solar optical fiber lighting system in Huashuyan Tunnel was shown in Figure 10 and Table 4.

The 3D illuminance simulation of solar optical fiber lighting system in Huashuyan Tunnel was shown in Figure 11. In the illumination simulation analysis, we took the closed space as the simulation environment without considering the effects of natural light outside and the LED lighting inside. According to "Specifications for Design of Ventilation and Lighting of Highway Tunnel," it could be seen from the simulation that, even not considering the contribution 


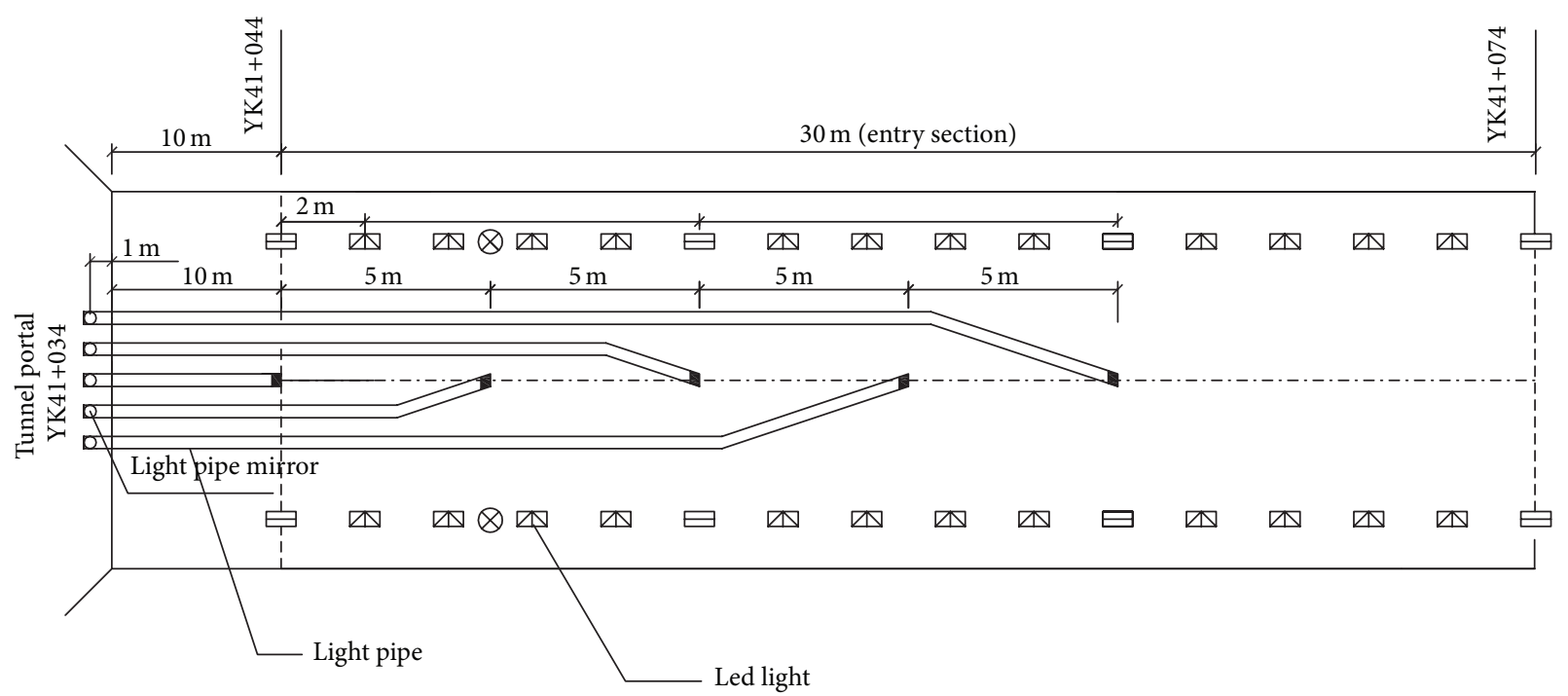

FIGURE 7: Design diagram of solar optical fiber lighting system in plan zone of Huashuyan Tunnel.

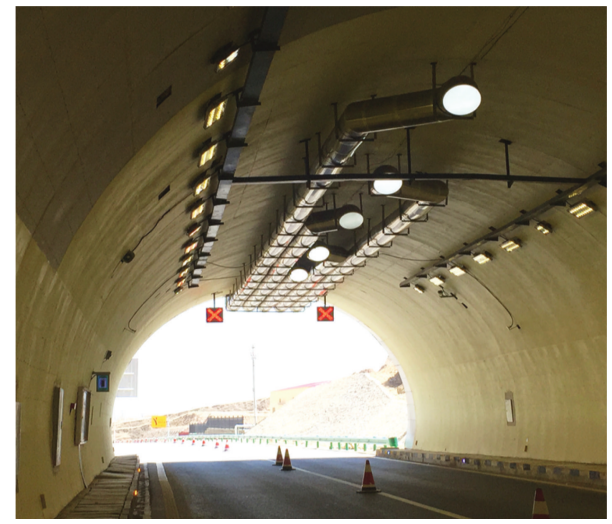

FIGURE 8: Light pipe installation in plan zone of Huashuyan Tunnel.

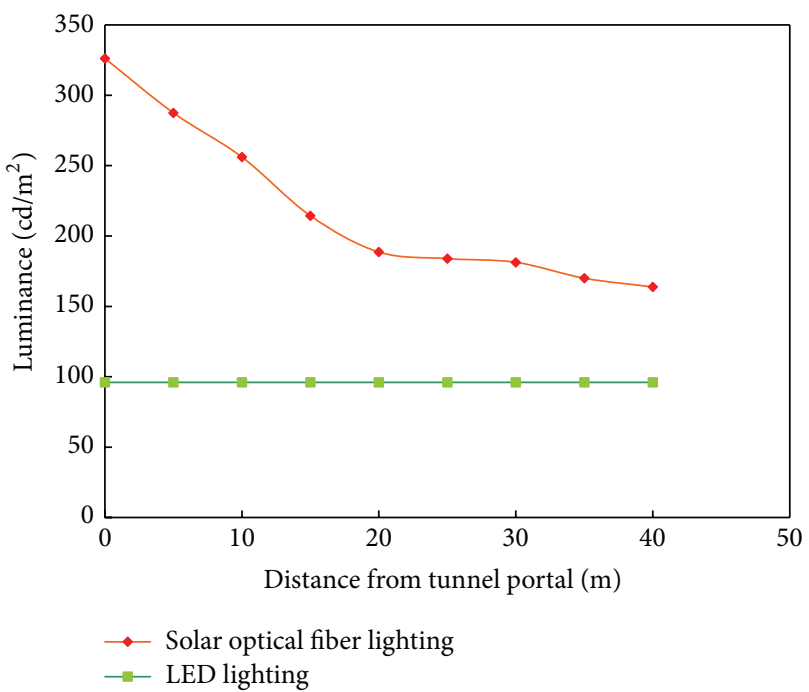

FIgURE 9: The average illuminance of solar optical fiber lighting in tunnel threshold zone in daytime in April.
TABle 4: The illuminance of solar optical fiber lighting system in Huashuyan Tunnel.

\begin{tabular}{lcc}
\hline Light pipe & $\begin{array}{c}\text { Average illuminance } \\
\text { (lux) }\end{array}$ & $\begin{array}{c}\text { Maximum illuminance } \\
\text { (lux) }\end{array}$ \\
\hline Number 1 & 1065 & 806 \\
Number 2 & 890 & 728 \\
Number 3 & 841 & 698 \\
Number 4 & 794 & 635 \\
Number 5 & 710 & 582 \\
\hline
\end{tabular}

of LED lighting, the lighting design of solar optical fiber lighting system in Huashuyan Tunnel still well met the enhanced lighting demand and verified its feasibility for highway tunnel.

3.5. Calculation of the Transmission Efficiency of Optical Fiber. We used the quartz multimode fiber with the diameter of $1 \mathrm{~mm}$ available for visible light transmission in the study, which had the attenuation of $20 \mathrm{~dB} / \mathrm{km}$ in the visible region and realized the practical applications of optical fiber lighting within the range of $200 \mathrm{~m}$. The relationship between the transmission efficiency and the length of optical fiber could be calculated according to the following formula and the transmission efficiency of the optical fiber at different length could be obtained as shown in Table 5 and Figure 12:

$$
\varphi=\frac{p_{o}}{p_{i}}=10^{-0.002 L}
$$

where $L$ was the length of the optical fiber.

The transmission efficiency of the optical fiber at different length could be obtained as shown in Table 5 .

It could be seen from Figure 12 that the transmission loss of optical fiber lighting system in the threshold zone of the tunnel was only $12.9 \%$, which suggested that the solar 


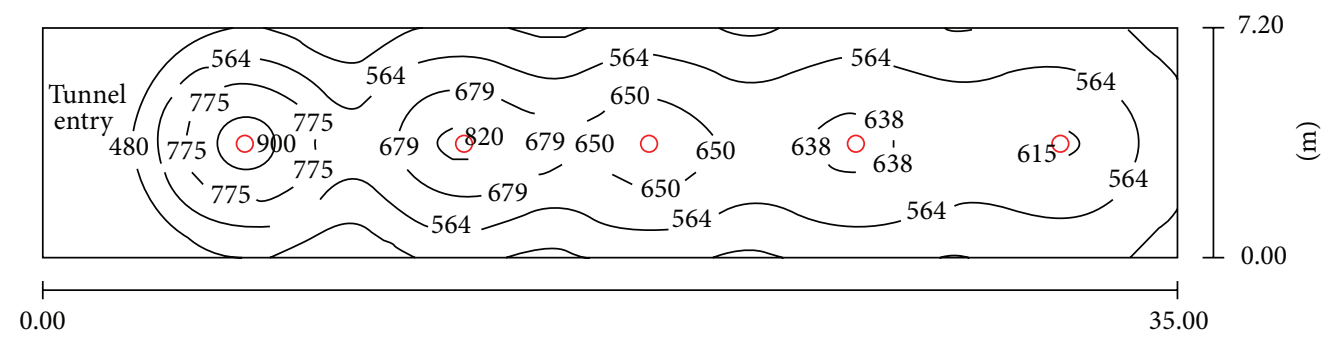

(m)

○iber optic irradiator

FIGURE 10: The isolux distribution of solar optical fiber lighting system in Huashuyan Tunnel.

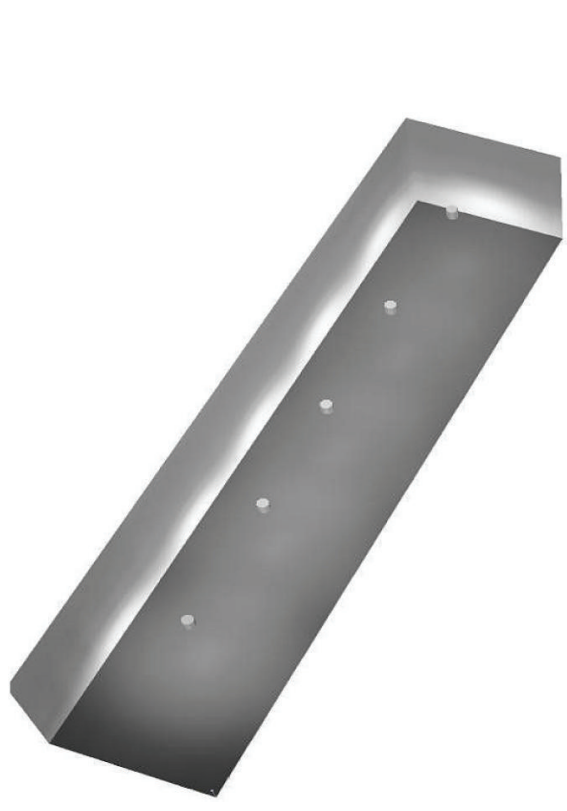

(a)

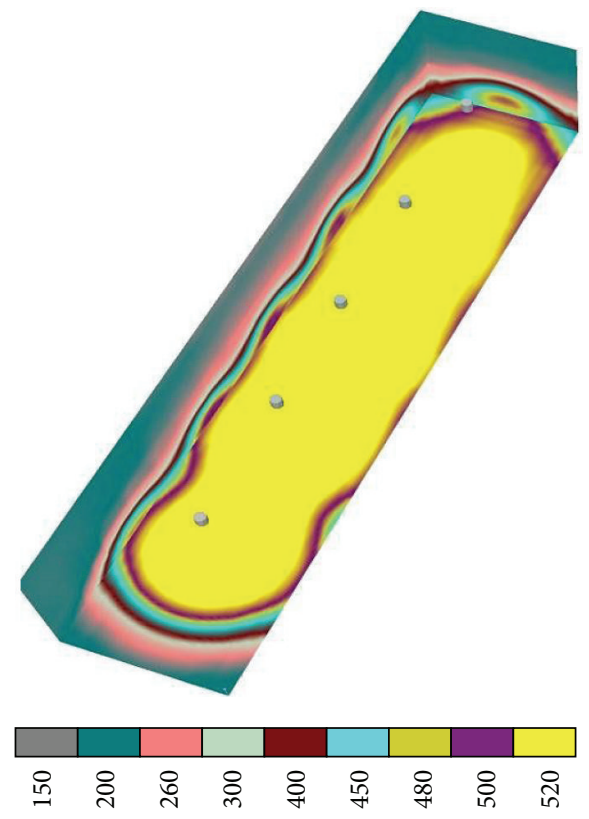

(b)

FIgURE 11: The 3D simulation illuminance of solar optical fiber lighting system in Huashuyan Tunnel.

TABle 5: The transmission efficiency of the optical fiber at different length.

\begin{tabular}{lccccc}
\hline Length of optical fiber & $10 \mathrm{~m}$ & $15 \mathrm{~m}$ & $20 \mathrm{~m}$ & $25 \mathrm{~m}$ & $30 \mathrm{~m}$ \\
\hline $\begin{array}{l}\text { Transmission } \\
\text { efficiency }\end{array}$ & $95.50 \%$ & $93.33 \%$ & $91.20 \%$ & $89.13 \%$ & $87.10 \%$ \\
\hline
\end{tabular}

optical fiber lighting applied in the threshold zone of $30 \mathrm{~m}$ for enhanced lighting for Huashuyan Tunnel was quite feasible in terms of light energy loss.

\section{Conclusion}

(1) As the lighting system of environmental protection and energy saving, solar optical fiber lighting system was quite suitably applied in the relatively small places with short transmission distance and small lighting area, which were

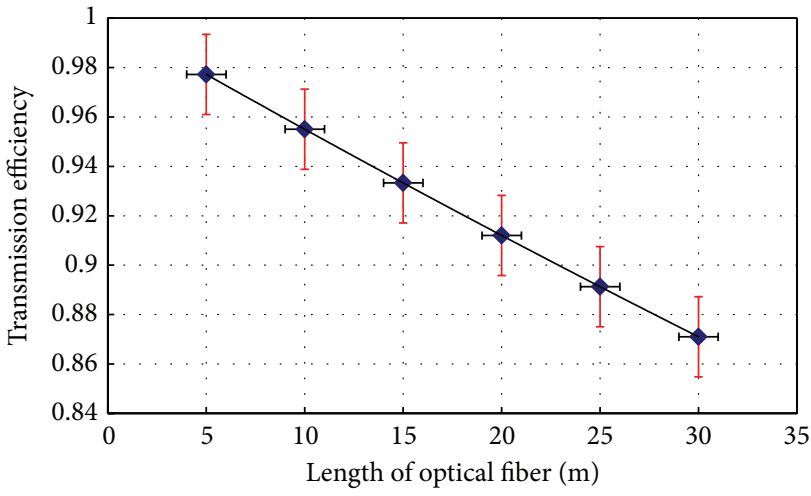

FIGURE 12: The transmission efficiency of the optical fiber at different length.

good in line with the requirements of enhanced lighting in the threshold zone of highway tunnel. 
(2) The design length of the optical fiber system in the threshold zone of the tunnel was related to the design speed, longitudinal slope, and overhead clearance of the tunnel. The design length of the optical fiber system of Huashuyan Tunnel was 30 meters by the calculation.

(3) The luminance requirement of enhanced lighting in the threshold zone of highway tunnel was related to the luminance outside the tunnel, the design speed, and the design traffic flow of the tunnel. The design luminance in the threshold zone of Huashuyan Tunnel was at least 83.47 lux according to the calculation.

(4) The number of optical guiding devices of solar optical fiber lighting system was determined considering the orientation of the tunnel, the width and height of the tunnel, and the environmental factors outside. A total of 5 light pipes were installed in Huashuyan Tunnel.

(5) The average luminance of solar optical fiber lighting in the threshold zone of Huashuyan Tunnel in daytime was $181.31 \mathrm{~cd} / \mathrm{m}^{2}$ at minimum, which well meet the basic design demand of $83.47 \mathrm{~cd} / \mathrm{m}^{2}$ by the onsite luminance experiment and analysis.

(6) The luminance of solar optical fiber lighting system in Huashuyan Tunnel well met the enhanced lighting demand and verified its feasibility for highway tunnel even not considering the contribution of LED lighting according to the 3D illuminance simulation results by DIALux software.

(7) The transmission loss of optical fiber lighting system in the threshold zone of Huashuyan Tunnel was only $12.9 \%$ according to the calculation, proving that solar optical fiber lighting applied in the threshold zone of $30 \mathrm{~m}$ for enhanced lighting of Huashuyan Tunnel was quite feasible.

Therefore, solar optical fiber lighting technology was proved to have a good application prospect in tunnel enhanced lighting by improving the quality of tunnel lighting, saving electrical energy and environmental protection.

\section{Conflict of Interests}

The authors declare that there is no conflict of interests regarding the publication of this paper.

\section{Acknowledgments}

The research work was supported by National Natural Science Foundation of China under Grant no. 51108216 and the Fundamental Research Funds for the Central Universities no. 2015JBM067 and no. 2015RC023. The authors are very grateful for the helpful comments and criticisms of the anonymous reviewers.

\section{References}

[1] C. Sapia, "Daylighting in buildings: developments of sunlight addressing by optical fiber," Solar Energy, vol. 89, pp. 113-121, 2013.

[2] D. Ning and D. Zhang, "Research on sunlight fiber lighting," Journal of Shaanxi University of Science and Technology, vol. 23, pp. 45-47, 2005.
[3] K. K. Chong and C. W. Wong, "General formula for on-axis sun tracking system and its application in improving tracking accuracy of solar collector," Solar Energy, vol. 83, no. 3, pp. 298305, 2009.

[4] P. Couture, H. Nabbus, A. Al-Azzawi, and M. Havelock, "Improving passive solar collector for fiber optic lighting," in Proceedings of the IEEE Electrical Power and Energy Conference (EPEC '11), pp. 68-73, IEEE, Winnipeg, Canada, October 2011.

[5] V. G. Gude, N. Nirmalakhandan, S. Deng, and A. Maganti, "Low temperature desalination using solar collectors augmented by thermal energy storage," Applied Energy, vol. 91, no. 1, pp. 466474, 2012.

[6] X. Xue, H. Zheng, Y. Su, and H. Kang, "Study of a novel sunlight concentrating and optical fibre guiding system," Solar Energy, vol. 85, no. 7, pp. 1364-1370, 2011.

[7] I. Ullah and S. Shin, "Highly concentrated optical fiber-based daylighting systems for multi-floor office buildings," Energy and Buildings, vol. 72, pp. 246-261, 2014.

[8] Mnistry of Transportation, Specifications for Design of Ventilation and Lighting of Highway Tunnel of China (JTJ026.1-1999), China Communication Press, Beijing, China, 2011.

[9] J. Yao, Design of sunlight direct enhaned illumination system on highway tunnel [Dissertation for the Master's Degree], Shanxi University of Science and Technology, 2014.

[10] A. Peña-Garćia, L.-M. Gil-Martín, R. Escribano, and A. EspínEstrella, "A scale model of tension structures in road tunnels to optimize the use of solar light for energy saving," International Journal of Photoenergy, vol. 2011, Article ID 313952, 9 pages, 2011.

[11] J. J. Buraczynski and T. K. Li, “Tunnel lighting systems," Tunnel Safety and Security, vol. 56, pp. 553-556, 2010.

[12] U.S. Department of Energy, Lighting Market Characterization, Solid-State Lighting Program, 2012.

[13] B. J. Huang, M. S. Wu, P. C. Hsu, J. W. Chen, and K. Y. Chen, "Development of high-performance solar LED lighting system," Energy Conversion and Management, vol. 51, no. 8, pp. 1669$1675,2010$.

[14] C. Kandilli, K. Ulgen, and A. Hepbasli, "Exergetic assessment of transmission concentrated solar energy systems via optical fibres for building applications," Energy and Buildings, vol. 40, no. 8, pp. 1505-1512, 2008.

[15] F. Wang and W. Long, "Application status and development prospect of solar lighting vessel technology," Building Science, vol. 24, pp. 109-113, 2008.

[16] H. J. Han, S. B. Riffat, S. H. Lim, and S. J. Oh, "Fiber optic solar lighting: functional competitiveness and potential," Solar Energy, vol. 94, pp. 86-101, 2013.

[17] M. Tekelioglu and B. D. Wood, "Solar light transmission of polymer optical fibers," Solar Energy, vol. 83, no. 11, pp. 20392049, 2009.

[18] C. Zidani, B. Benyoucef, and N. Madini, "Exergetic assessment of transmission-concentrated solar energy systems via optical fibres for building applications," International Journal of Exergy, vol. 11, no. 2, pp. 216-228, 2012.

[19] Ministry of Housing and Urban-Rural Development of the People's Republic of China, "Standard for day lighting design for building," GB 50033-2013, China Architecture \& Building Press, Beijing, China, 2013. 
[20] Ministry of Housing and Urban-Rural Development of the People's Republic of China, Green Building Assessment Standard(GB/T 50378-2006), China Architecture \& Building Press, Beijing, China, 2006.

[21] X. Qin, Q. Wei, L. Wang, and Y. Shen, "Solar lighting technologies for highway green rest areas in China: energy saving economic and environmental evaluation," International Journal of Photoenergy, vol. 2015, Article ID 926235, 10 pages, 2015. 

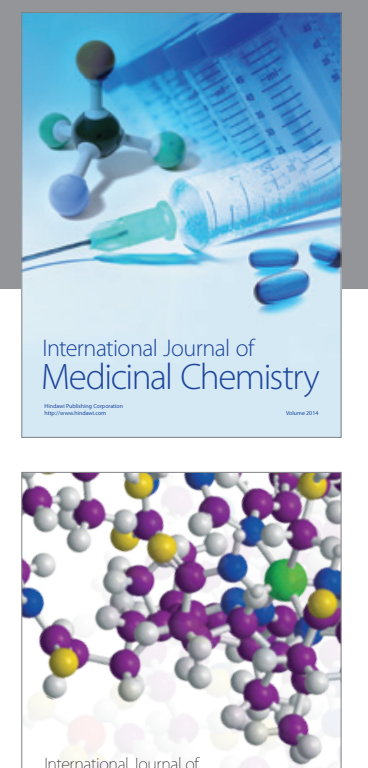

\section{Carbohydrate} Chemistry

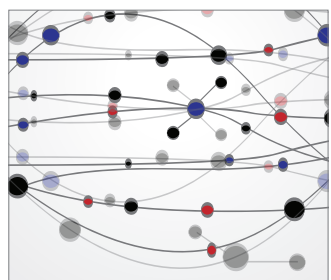

The Scientific World Journal
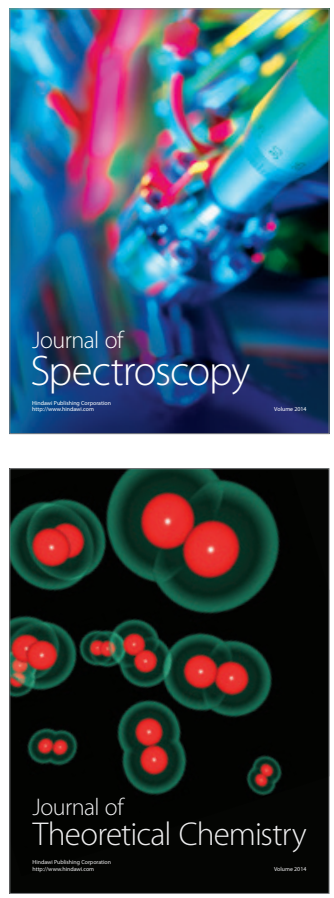
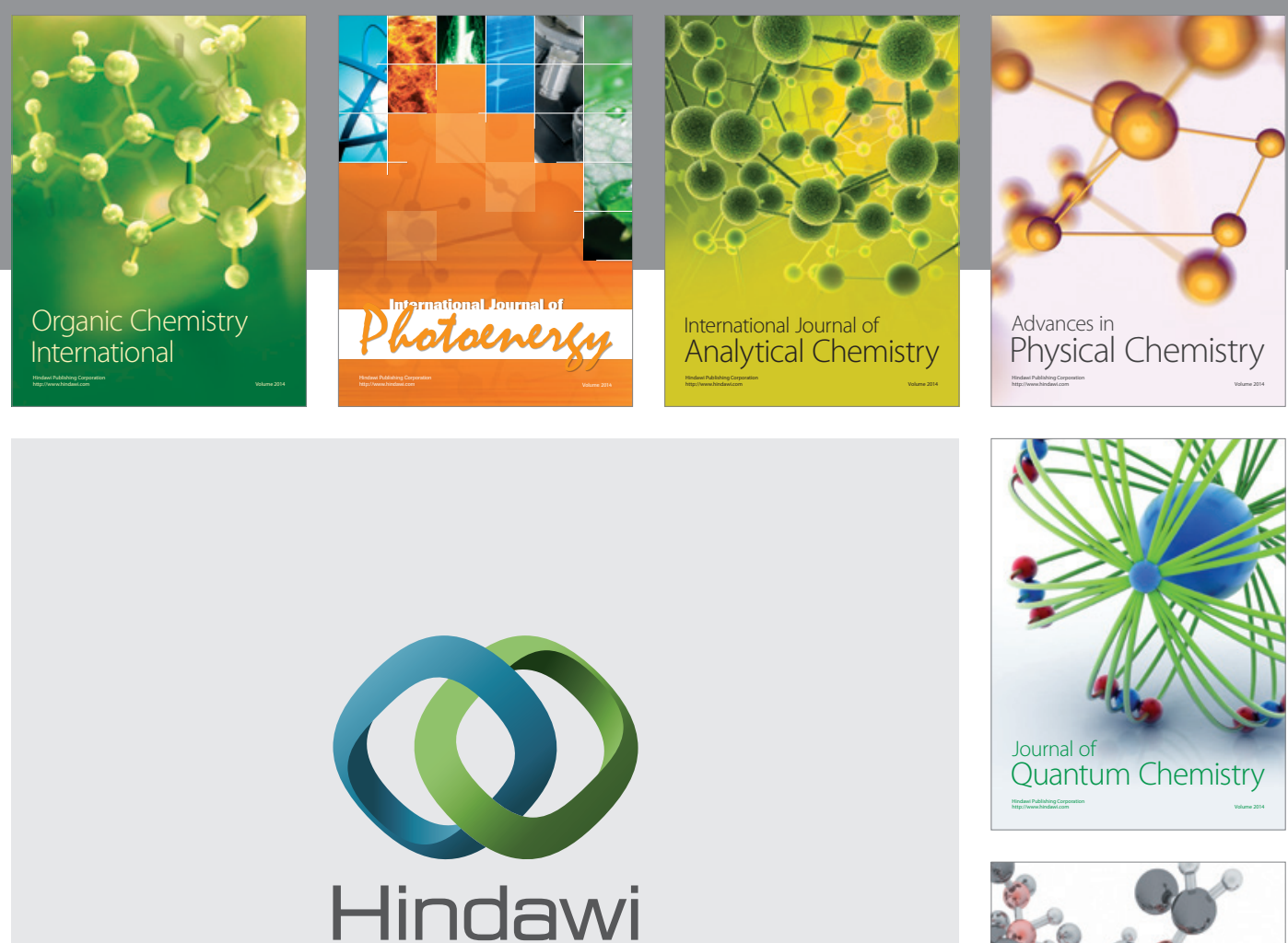

Submit your manuscripts at

http://www.hindawi.com

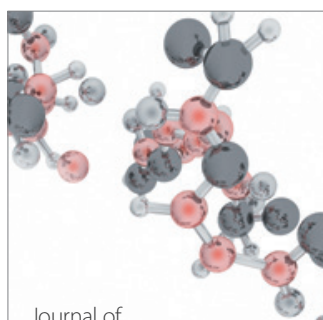

Analytical Methods

in Chemistry

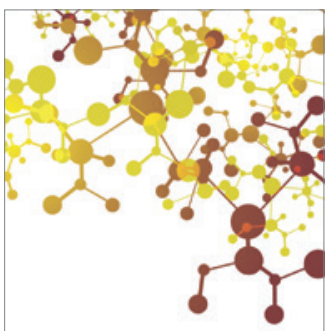

Journal of

Applied Chemistry

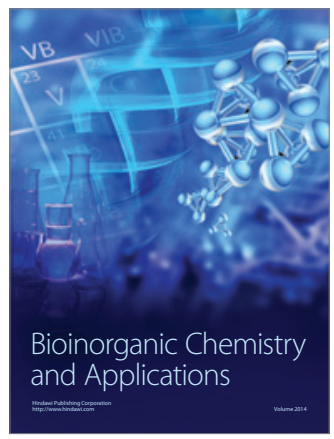

Inorganic Chemistry
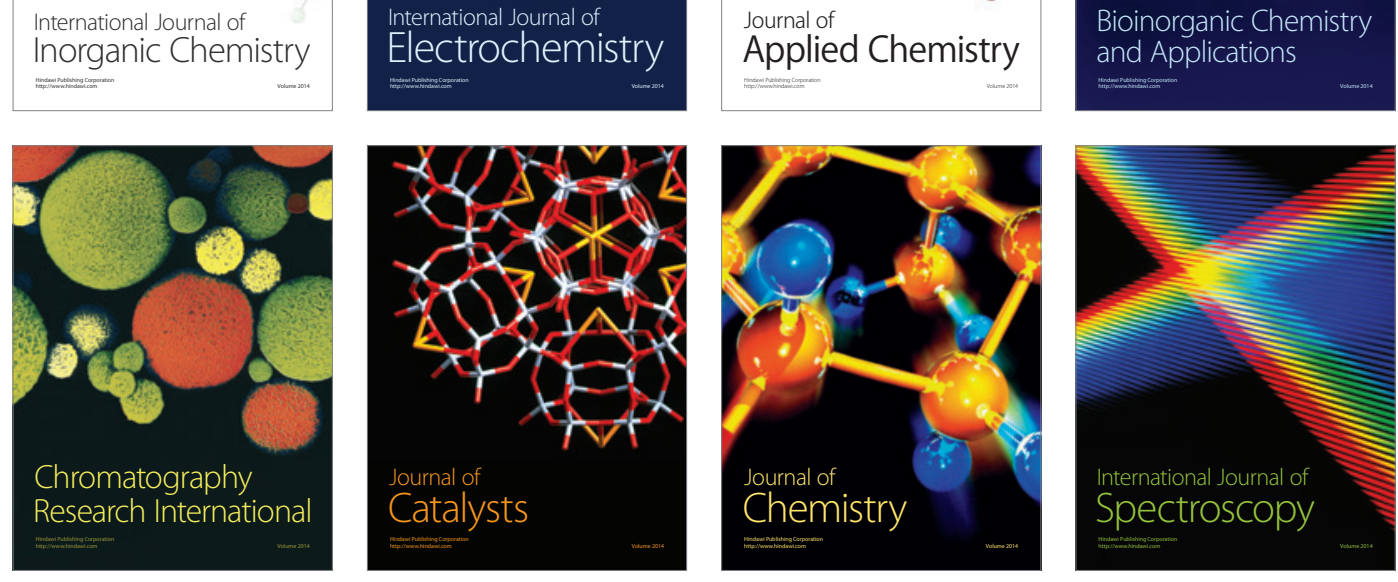